\title{
La ciencia de la transdisciplinariedad o la política compleja. (Las fronteras entre el derecho y la política)
}

ELVIO GALATI*

Artículo recibido: 1 de junio de 2014

Artículo aprobado: 16 de septiembre de 2014

Doi: dx.doi.org/10.12804/desafios27.01.2015.03

Para citar este artículo: Galati, E. (2015). La ciencia de la transdisciplinariedad o la política compleja. (Las fronteras entre el derecho y la política). Desafios 27(1), 83-120. doi: dx.doi. org/10.12804/desafios27.01.2015.03

\section{Resumen}

Se analiza la posición de dos juristas trialistas respecto de la Política. Una posición es crítica, en el sentido de asociar la Política al poder, la arbitrariedad, la discrecionalidady al marginar a ese ámbito las cuestiones de justicia, que no forman parte del Derecho para el positivismo. Mientras que el trialismo incorpora en el mundo jurídico la dimensión axiológica, analizable cientificamente, lo que asegura la idoneidad y la igualdad. La otra posición es menos critica con la Politica y la plantea como una superación del Derecho en la convivencia y el amor. La Política permite comprensión, participación, comunicación, de las que suele carecer el Derecho, tanto más si es mera normatividad. La posición del pensamiento complejo, que llama a

\footnotetext{
* Profesor en Ciencias Jurídicas y posdoctor en Derecho. Profesor asociado de Ética profesional en la Universidad Abierta Interamericana, docente regular de Filosofía del Derecho en la Universidad Nacional de Rosario (UNR) y profesor titular de Teoría jurídica en la Universidad de Concepción del Uruguay. Miembro del Programa Pensamiento Complejo del Centro de Estudios Interdisciplinarios de la UNR. Rosario, Argentina. Correo electrónico: elviogalati@gmail.com
} 
no anular ni reducir una posición en la otra, sino a una convivencia dialógica de antagónicos en una unidad que los integre, puede llamar a complementar estas dos posiciones en la unidad de la ciencia de la transdisciplinariedad, ya que el problema del ser bumano no puede ser abordado por disciplina alguna de manera aislada. La ciencia de la transdisciplinariedad podrá entonces coordinar los aportes de cada una de las ciencias con miras a solucionar el problema del destino bumano.

Palabras clave: Derecho, politica, trialismo, complejidad, transdisciplinariedad.

\title{
The Science of Transdisciplinarity or Complex Politics: The Borders between Law and Politics
}

\begin{abstract}
This article analyzes the position of two legal points of view regarding politics. One of the positions is critical, in the sense of associating politics with power, arbitrariness, discretion and marginalizing issues of justice, i.e., issues which are not part of law according to positivism. On the other hand, trialism incorporates axiological dimensions, the scientific analysis in the legal world, and ensures adequacy and equality. The second position is less critical of politics and sees it as an improvement of law in terms of coexistence and love. Politics allows understanding, participation, communication, features which law often lacks, even more so if it is mere regulations. The position of complex thinking, which suggests neither negating nor reducing a position into another, but a dialogical coexistence of antagonists in a unit that integrates them, proposes complementing these two positions in the unity of the science of transdisciplinarity. Since the human problem cannot be tackled by any discipline in isolation, the science of transdisciplinarity will be able to coordinate the contributions of each of the sciences in order to solve the problem of buman destiny.
\end{abstract}

Keywords: Law, politics, trialism, complexity, transdisciplinarity.

\section{A ciência da transdisciplinaridade ou a política complexa. (As fronteiras entre o direito e a política)}

\section{Resumo}

Se analisa a posição de dois juristas trialistas respeito da Política. Uma posição é crítica, no sentido de associar a Política ao poder, a arbitrariedade, a discricionariedade 
e ao marginar a esse âmbito as questões de justiça, que não formam parte do Direito para o positivismo. Enquanto que o tribalismo incorpora no mundo jurídico a dimensão axiológica, analisável, cientificamente e assegurando a idoneidade e a igualdade. A outra posição é menos crítica com a Política e a expões como uma superação do Direito na convivência e o amor. A Política permite compreensão, participação, comunicação das que sole carecer o Direito, tanto mais se é mera normatividade. A posição do pensamento complexo, que chama a não anular nem reduzir uma posição na outra, mas a uma convivência dialógica de antagónicos em uma unidade que os integre, pode chamar a complementar estas duas posições na unidade da ciência da transdisciplinaridade. Devido a que o problema do ser bumano não pode ser abordado por disciplina alguma de maneira isolada. A ciência da transdisciplinaridade poderá então coordenar os aportes de cada uma das ciências com miras a solucionar o problema do destino bumano.

Palavras-chave: Direito, política, trialismo, complexidade, transdisciplinaridade.

\section{Introducción}

Este trabajo intentará responder a la pregunta por las relaciones entre el Derecho y la Política. Cabe preguntarse si hay que negar a la Política como disciplina por su costado oportunista vinculado al poder o alabarla por su costado armonizador tendiente a la convivencia. Cabe preguntarse si hay que negar al Derecho como disciplina formal, despegada de la realidad, burocrática o alabarla por su previsibilidad y portadora de la crítica de la justicia. ¿Qué pensamiento permitiría dicha convivencia de contradictorios? El marco teórico de la teoría trialista del mundo jurídico creada por Werner Goldschmidt y el pensamiento complejo de Edgar Morin guiarán, en gran medida, la respuesta a la que se arribará.

El trabajo se estructurará en cuatro partes. En la primera parte se verá la posición originaria del trialismo respecto de la Política, donde se tratarán argumentos que desarrolló Goldschmidt para criticar a la política partidaria. En la segunda parte, con el continente político del Derecho, se verá absorbido a este por la Política, según una de las últimas versiones clásicas del trialismo. En la tercera parte, al hablar de la ciencia de la transdisciplinariedad se verá cómo se pone en 
marcha la convivencia humana. A medida que se van desarrollando los argumentos de ambas posturas, se verán también las coincidencias de estas con el pensamiento complejo de Edgar Morin. Y en la cuarta parte, se tratan casos concretos en donde el Derecho y la Política, por medio de las cuestiones políticas justiciables, plantean ámbitos de justicia y de diálogo.

\section{El trialismo ${ }^{1}$ originario y la Política}

1. Goldschmidt califica con una neutralidad cercana al desprecio a la Política. De hecho, critica a Hans Kelsen, quien, producto de la purificación, envía las cuestiones de la justicia a la Política. Dice el jurista vienés:

El derecho positivo no permite la elección de la solución 'justa' entre las diversas posibilidades contenidas en el marco de la norma, con lo cual el problema por resolver no es de la competencia de la ciencia del derecho sino de la política jurídica (Kelsen, 1992, p. 169).

Señala Goldschmidt que "el ingrediente valorativo es excomulgado del ámbito de la ciencia y vagabundea por el campo de la Política" (Goldschmidt, 1987, p. XVII). En otra oportunidad, señala cómo la justicia limita a la política.

[...] el criterio de la hermeticidad o de la plenitud del ordenamiento normativo aspira decretar una política de no-intervención de la justicia en el orden de repartos (a través de la integración del ordenamiento normativo). Esta no-intervención solo será tolerable si el orden de repartos no se desenvuelve con una injusticia insoportable (Goldschmidt, 1987, p. 338).

\footnotetext{
1 La teoría trialista del mundo jurídico considera que el Derecho está compuesto por las dimensiones sociológica, normológica y axiológica y el pensamiento complejo es una filosofía que entiende a todo fenómeno como compuesto por un sistema de elementos heterogéneos que no obstante pueden convivir concurrente, antagónica y complementariamente.
} 
En otra ocasión, el jurista germano-español relaciona el reparto, adjudicación humana de potencia e impotencia - que perjudica o beneficia al ser-con el poder. Si bien parece que solo el reparto autoritario - que se impone- hace uso de este valor, puede pensarse que los repartidores autónomos - que acuerdan- deben también luchar por su autonomía, a fin de alcanzarla, mantenerla, o expandirla. "Se trata [...] en los repartos de instrumentos políticos, porque la política es la lucha por el poder. Más exactamente estamos en presencia de la lucha por el poder sobre hombres" (Goldschmidt, 1986b, p. 786). Dice el maestro "[...] en el Trialismo el Derecho, lejos de ser algo inofensivo como conductas en interferencia intersubjetiva o un conjunto de normas, es la realidad política con su lucha encarnizada por el poder humano" (Goldschmidt, 1986b, p. 786).

Julio Raffo, al comentar el contenido de un libro no publicado del jurista argentino Carlos Cossio, creador de la egología, señala el tabú de la justicia:

[...] ni la justicia ni la injusticia pueden ser temas dentro de la sociedad capitalista; ambos son temas subversivos [...]. Sobre ambos temas se impone, pues, en principio, el silencio [...]. Y por ello al abogado de la sociedad capitalista se le inculca la superficialidad de la reflexión filosófica sobre el Derecho y la banalidad o sinsentido de la reflexión sobre la Justicia (Raffo, 2007, p. 212).

2. Otra descalificación merece la Política cuando Goldschmidt critica la distinción entre cuestiones de lege lata y lege ferenda. Lege lata alude a las interpretaciones del derecho vigente. Y lege ferenda son los argumentos que se proponen para modificar la norma vigente. Sería tanto como la diferencia entre el derecho y política jurídica, desde la terminología del positivismo jurídico. En efecto,

[...] si rechazamos de la ciencia jurídica e inclusive de cualquier ciencia la investigación de la justicia, por no tratarse de un tema objetivo, y, por ende, científicamente analizable, sino de un factor subjetivo de decisiones políticas, el jurista no da normas, ni 
normas generales (como el legislador), ni normas individuales si aquellas dan margen a diversas posibilidades de realizaciones (como en este supuesto el juez, o el funcionario administrativo en actos discrecionales). [...] La actividad del jurista de lege lata consiste entonces, a imagen y semejanza de la de un vendedor en un negocio, en colocar sobre el mostrador de la tienda, cual sendas mercaderías, las diferentes posibilidades de interpretación de las normas establecidas; el político, como cliente y comprador, adquiere de lege ferenda cualquiera de ellas conforme a las misteriosas reglas de motivación del acto humano. Estas reglas inescrutables esconden la motivación de justicia (Goldschmidt, 1987, p. 386).

3. En otra oportunidad señala cómo debemos cuidarnos de las actitudes de los partidos políticos, ya que por la búsqueda del poder, pueden mostrar una realidad fraccionada.

[...] poquísimas veces lucha una persona o un grupo desinteresadamente contra la injusticia hecha a otra persona u otro grupo. [...] la lucha política que utiliza como uno de sus medios más eficaces, el de denunciar las injusticias que comete el partido opuesto, a fin de llegar al poder o de conservarlo. [...] esquivar el espejismo de considerar automáticamente como mejor a quien lucha por una causa justa que a quien defiende una posición injusta. Denunciar desde el llano injusticias, no significa omitirlas desde la cumbre (Goldschmidt, 1987, p. 390).

4. Asimismo, opone la aristocracia del científico a la sabiduría del lego, en donde se encontraría el político en ciernes. Señala Goldschmidt:

[...] los alumnos no son de ninguna manera los jueces de sus educadores, puesto que peritos solo pueden ser enjuiciados por peritos. Ni que decir tiene que hacemos referencia a alumnos en sentido estricto, o sea, a alumnos que asisten a la enseñanza de sus profesores y no a personas inscritas como alumnos, pero exclusivamente consagradas a la dirección política de una asociación estudiantil (Goldschmidt, 1986a, p. 288). 
En este caso, no se tiene en cuenta la complejidad del acto pedagógico, que necesita incluir el juicio de uno de los sujetos de la relación educativa. No se olvide que en su obra principal Goldschmidt privilegia el reparto autónomo, base de la democracia. Además, Ciuro Caldani señala que la complejidad de la vida exige que para una convivencia plena tanto la aristocracia como la democracia se promuevan mutuamente (Ciuro Caldani, 1991).

Tristemente, relacionados con este tema se encuentran aquellos que acceden a la Universidad y aprovechan el poder para destruir el saber. "[...] la destrucción del saber-poder llega a ser en ciertos casos el instrumento con el que jóvenes pertenecientes mayoritariamente a la clase media hacen sus primeras experiencias partidistas en la conquista de votos" (Ciuro Caldani, 1992, p. 47). Por mi parte, sostengo que la carrera partidista del alumno debe ser una actividad extra, pero no sustitutiva del aprendizaje académico, es decir, debe ser una carga extra para el estudiante, pero no motivo para que hiberne o mantenga indefinidamente sus estudios. Así como a muchos auxiliares ingresar en la docencia y perfeccionarse les significa un esfuerzo extra combinado con el estudio de la carrera, lo propio debe ocurrir con la combinación entre aprendizaje de la carrera y los primeros pasos en la política partidista.

5. En otro lugar señala:

La doctrina de la ley natural emigra, bajo el impero del positivismo, de la filosofía del Derecho, y aparece en la forma de innumerables exigencias concretas en la política de la legislación, que, precisamente como política, está en oposición a la ciencia (Goldschmidt, 1986a, p. 5).

No es casual que un ex ministro del Poder Ejecutivo (PE) haya mandado a los científicos a lavar los platos. Decía Weber lo que alguien debe decirle a un joven que pide consejo acerca de ingresar en la actividad académica: “[...] ‘ ¿cree usted que podrá soportar sin amargarse y sin corromperse el que año tras año pase 
por delante de usted una mediocridad tras otra?"' (Weber, 1995, p. 190). Luego señala la función del profesor, en cuanto tiene " [...] la obligación de crear claridad y sentimiento de la responsabilidad. Y [...] será tanto más capaz de realizar esta obra cuanto más concienzudamente evite por su parte el deseo de imponer o sugerir su propia postura personal a sus oyentes" (Weber, 1995, p. 223).

Weber señala la diferencia de la política con la ética:

La ética acósmica nos ordena 'no resistir el mal con la fuerza', pero para el político lo que tiene validez es el mandato opuesto: has de resistir al mal con la fuerza, pues de lo contrario te haces responsable de su triunfo. Quien quiere obrar conforme a la moral del Evangelio debe abstenerse de participar en una huelga, que es una forma de coacción [...] debe abstenerse de hablar de 'Revolución' (Weber, 1995, p. 162).

Sobre el tema señala Goldschmidt la falta de cientificidad de la Política:

Los medios de la política de llegar al poder se encaminan hacia la captación de la voluntad de los conciudadanos. A este efecto se esgrimen argumentos, se apela a sentimientos, se despiertan apetencias. Los discursos políticos constituyen [...] muchas veces 'música hablada', o sea, yuxtaposiciones gramaticalmente correctas de palabras con cargas emocionales, pero sin sentido verificable (Goldschmidt, 1986a, p. 320).

6. Cuando la Corte Suprema de Justicia de la Nación (CSJN) estaba de acuerdo con una solución del PE o del Congreso, era una cuestión política no justiciable, y cuando estaba en desacuerdo era el acto o la norma inconstitucional. Así nació el per saltum, mediante el caso "Dromi S. avocación en autos 'Fontela C. Estado Nacional"', fallado por la mayoría automática de la CSJN el 6 de Septiembre de 1990, en donde avaló el salto de instancia contrariando la normatividad, ya que el Congreso recién sancionó 
la Ley 26.790 en 2012. Allí se vale de la justicia: “[...] que el marco normativo que procura la eficiencia del Tribunal no conspire contra la eficiencia de su servicio de justicia al que, en rigor, debe tributar todo ordenamiento procesal" (consid. 5). Incluso en el mismo fallo, la Corte habla del respeto a los otros poderes:

$[\ldots]$ lo vinculado con el gobierno, prudencia y sabiduría relativas a la administración de la hacienda y patrimonio públicos, y al diseño de las políticas respectivas, es ya materia propia de los otros poderes. Solo compete al Tribunal, en punto a los actos dictados en esas materias, decidir, en causas judiciales, acerca de su legalidad, no de su acierto, oportunidad y conveniencia (consid. 18).

El Alto Tribunal hizo esta consideración para desacreditar el cuestionamiento que Fontela hacía de la privatización de Aerolíneas Argentinas ¿Por qué no se respetó la reglamentación que el Congreso hizo del recurso extraordinario? ¿Acaso el Tribunal no debe respetar la conveniencia de instaurar una o dos instancias previas a la última?

6.1. En el caso "Comunidad Homosexual Argentina", fallado por la mayoría automática de la CSJN el 22 de noviembre de 1991, valorando negativamente la homosexualidad, esconde la misma Corte dicha motivación en la calificación del juicio administrativo como una cuestión política no justiciable. ¿Acaso no era político el establecimiento de las instancias judiciales previas a la Corte y los supuestos de la competencia originaria? Nótese que los firmantes del fallo son las mismas personas: la denominada "mayoría automática" de la época de la administración Menem. Estos vaivenes escondían, como dice Goldschmidt, las motivaciones de la justicia. Y lo peor era que muchas veces, dichas resoluciones, en vez de basarse en la justicia, se basaban en el poder, o en la conveniencia de los poderosos. Todos los individuos que pretenden ser indiferentes a las consideraciones sobre lo recto y lo justo juzgan acerca de lo justo y de lo injusto, sea de modo implícito o admitiéndolo (Ciuro Caldani, 1976, p. 41). 
6.2. Un caso similar al de la "CHA" se planteó con el fallo "Asociación Lucha por la Identidad Travesti y Transexual c. Estado Nacional", fallado por la Corte el 21 de noviembre de 2006. Con otra conformación, en este caso, la Corte sí acepta el reconocimiento de la personalidad jurídica a una asociación que agrupaba a travestis y transexuales. Frente a este cuadro de situación, la justicia le preguntaría a la Política —según Kelsen- por qué denegar en uno lo que se concede en otro. La Política respondería que por cuestiones de conveniencia, y la justicia reclamaría que lo que se da a uno en unas condiciones, no puede negarse a otro en similares condiciones, precisamente porque en eso consiste la igualdad. Esto muestra cómo la Política esquiva la justicia, entendiendo concretamente por tal la igualdad.

7. Los nuevos tiempos propenden a debilitar a la Política como lealtad, debido a la existencia de mayores organismos de control: la Auditoría General de la Nación, el Defensor del Pueblo, el Ministerio Público, los organismos internacionales como la Corte Interamericana de Derechos Humanos, las organizaciones que protegen derechos de incidencia colectiva, etc. Todos los cuales implican una exigencia de rendición de cuentas, incompatible con criterios discrecionales, es decir, de mérito, oportunidad, conveniencia, etc.

8. Una crítica recibe el Derecho de la Política: “[...] lo jurídico puede ser visto como algo potencialmente nocivo, rara mezcla de legalismo, formulismo y burocracia judicial [...]" (Sagüés, 1978, p. 3). Lo cual es consecuencia de la reducción normativista. Morin también señala que:

[...] la responsabilidad puede llevarnos a asumir combates mortales para proteger vidas, defender nuestra comunidad, mantener el derecho. Pero [...] la lucha a muerte no podría entrañar la reducción del enemigo a un ser abyecto, a un animal dañino, nunca debemos dejar de comprenderlo, es decir situarlo, contextualizarlo, continuar reconociéndolo como ser humano (Morin, 2006, p. 135). 
9. Por la falta de tratamiento de una idea general, que es el valor, se dan las consecuencias negativas que señala Goldschmidt:

Los autores de normas, con el pretexto de la acientificidad de la justicia, se ven exentos de la obligación de justificarlas dikelógicamente. Ello les permite redactarlas con exclusiva preocupación política. Luego los aplicadores de normas [...] exentos del deber de justificar dikelógicamente su elección hermenéutica, tienen [...] la oportunidad de escoger la interpretación políticamente favorable de la que hacen uso con excesiva frecuencia. Al hablar de 'política' hacemos referencia a cualquier tipo de consideración de conveniencia, trátese de alta política, oportunismo personal o satisfacción de pasiones elevadas o bajas. Por consiguiente, el Positivismo Jurídico [...] abre las puertas a la más absoluta arbitrariedad (Goldschmidt, 1987, p. 106).

10. En cambio, si la interpretación consiste en la averiguación de la intención del legislador, o en el fin que tuvo en miras al legislar, lo que respeta su reparto, es decir, su voluntad adjudicadora, el encargado del funcionamiento de la norma deberá justificar el apartamiento de dicha voluntad o fin, exponiendo las razones. No se ocultará en la voluntad de la ley o en la politicidad de la interpretación, sino que deberá dar las razones de justicia para apartarse de la norma. ¿Quién diría que un trialista protegería tanto la voluntad repartidora expresada en la normatividad? Y así podrá controlárselo, la ciencia jurídica se vuelve más previsible, transparente. El marco de posibilidades que señala Kelsen como integrante de la interpretación de las normas es el marco de la arbitrariedad, el descontrol, el marco de la Política. Claro que cuando el juez justifica dikelógicamente su apartamiento de la ley, no lo hace ocultándose en la actuación del "Derecho" o en la Constitución, sino que evidencia su opción. Y no encubre en realidad algo que es opinable, y que, como tal, debería formar parte del funcionamiento de la democracia, es decir, la elección de los jueces. 
11. Luego alude Goldschmidt a una de las principales críticas a los políticos: la mentira. "[...] la posibilidad de esconder los verdaderos móviles detrás de pretextos [...], la que aprovechan a veces los repartidores, sobre todo los políticos [...], prototipo de poderosos interesados [...], quienes suelen esgrimir la pseudooposición de individuo y sociedad [...]" (Goldschmidt, 1986a, p. 383). Cada palabra del jurista germano-español es un llamado de atención hacia la Política. Dice al condenar la moral doble: "El conductor no debe, bajo el pretexto de la defensa de la comunidad, que además sería una razón aparente, asegurar su propio poder privilegiado" (Goldschmidt, 1986a, p. 341). Lo que implica ir contra su esencia misma, que es la adquisición y/o mantenimiento del poder.

12. Un ámbito en donde deberían desaparecer paulatinamente las mezquindades y los amiguismos consecuentes, que asignan puestos por lealtades y cercanías, más que por méritos e idoneidad, es la Universidad. La falta de concursos docentes y los nombramientos interinos que pueden reordenarse, suspenderse por razones administrativas, implican otro golpe al Derecho, justificado desde la Política. "Los políticos [...] se esfuerzan en invadir el campo de los repartos aristocráticos y en politizarlos." (Goldschmidt, 1986a, p. 325). Nocivas son también las palabras de Bismark: “la política no es una ciencia exacta', 'la política no es una ciencia como muchos señores profesores se figuran, sino un arte"' (Ciuro Caldani, 1976, p. 45). Decir esto y mencionar a la arbitrariedad son una y la misma cosa.

13. Un acertado juicio realizó Goldschmidt al hablar de los partidos políticos y la justicia, señalando que promover la justicia significa ir en contra de la Política.

Los hombres cuya profesión consiste en la política intentan disminuir el número y la importancia de los repartos aristocráticos, puesto que tales repartos deben ser sustraídos de la influencia de la misma. Si, por ejemplo, el nombramiento de todos los titulares de puestos de educación y enseñanza solo se hiciere en atención a la capacidad de los aspirantes, no se puede recompensar con 
estos puestos a los miembros del partido, ni puede la esperanza de tal recompensa originar ningún ingreso en el partido (Goldschmidt, 1986a, p. 289).

13.1. Cabe agregar una anécdota narrada por Julio Raffo, según le contó a su vez José Vilanova sobre Cossio, que este dedica la primer edición de su teoría egológica, entre otros, a Ambrosio Gioja, quien era su discípulo y adjunto en la cátedra que titularizaba en la UBA el creador de la egología. Preguntando acerca de lo que Gioja haría si echaban a Cossio aquel dijo que seguiría siendo adjunto, pero que no ocuparía su cátedra. Echado Cossio en 1956, Gioja es nombrado titular. Requerido acerca de la razón por la cual había incumplido lo prometido, comete la falta normativista. Explica que a Cossio lo habían echado de la cátedra $A$ y que a él lo habían nombrado en la cátedra $B$ que se encontraba vacante. También relata el académico que Gioja desarrolló a Kelsen en lugar de la egología (Raffo, 2007). Este es un claro ejemplo del acceso a un puesto público por lealtad y alegación de una norma para justificar una conducta, desoyendo una conducta anterior. Se evidencia el conflicto entre legalidad y legitimidad, entre norma y justicia.

13.2. Julio Raffo también relata los inconvenientes que Cossio tuvo a la hora de querer publicar su libro Ideología y Derecho. Fue acusado de que lo podía hacer mejor, que la obra era extensa, que no estaba dentro de la orientación de la empresa, el estilo literario y la censura (Raffo, 2007, pp. 206-208). Cossio señala que al Poder Judicial se entra y se progresa por el padrinazgo. Raffo, atinadamente, señala que "Cossio escribió esto mucho antes de que la selección y promoción de los jueces nacionales y federales se realizara mediante los concursos que organiza el Consejo de la Magistratura" (Raffo, 2007, p. 213). De acuerdo con la Ley 24.937, dicho organismo, que se encarga de la selección y administración del Poder Judicial (art. 114, CN.), se componía de 20 miembros: cuatro jueces, cuatro abogados, un representante del PE, otro de la CSJN, dos académicos y ocho legisladores. Respecto de las mayorías necesarias para su funcionamiento, se requería de los dos tercios de los presentes para iniciar el procedimiento de remoción 
de los magistrados $\left(\operatorname{art} .7,7^{\circ}\right)$; y lo mismo se requería para las sanciones $\left(\right.$ art. $\left.7,12^{\circ}\right)$. Para remover a sus miembros se requería el voto de las tres cuartas partes de los miembros totales del cuerpo (art. $7,14^{\circ}$ ). El quorum era de doce miembros y las decisiones se tomaban por mayoría absoluta de los presentes (art. 9). Con esta composición, ningún grupo podía decidir o bloquear por sí el quorum o las decisiones. El oficialismo tenía cinco representantes. Porque de los ocho legisladores, dicha cantidad se dividía por dos, al haber dos cámaras en el Congreso, y de los cuatro, solamente dos legisladores correspondían al partido con mayor representación legislativa, uno por la primera minoría y el otro por la segunda $\left(\right.$ art. $\left.2,3^{\circ}\right)$. Y los no oficiales llegaban a la cantidad de quince. Las dos terceras partes se cubrían con trece consejeros, las tres cuartas partes con quince y la mayoría absoluta con once. Con la reforma de la Ley 25.876, el número de integrantes se redujo a trece, correspondiendo tres a los jueces, dos a los abogados, uno al PE., uno a la Academia y seis a los legisladores; y. en este último caso, van dos por el partido oficial y uno por la primer minoría, por cada Cámara del Congreso. Nótese que el único estamento que mantiene su representación es el correspondiente al oficialismo. Antes tenía cinco y ahora también. Antes los no oficiales subían a quince y hoy bajan a ocho. Para iniciar la remoción se necesitan dos tercios de los presentes, es decir, nueve, número al que no llegan los "no oficiales", que reúnen ocho; y para las sanciones mayoría absoluta, es decir, siete votos. Aquí, los dos tercios solo pueden reunirse con los votos del oficialismo.

Se adujo que se quería agilizar un componente del funcionamiento del Poder Judicial, aunque por otro lado se acusaba al gobierno de querer manipularlo. La composición de un organismo de control no debe tener preponderancia de elementos pertenecientes a aquello que se debe controlar, ni tampoco preponderancia político-partidaria.

Predominan por la Ley 25.876 los representantes políticos, frente a los judiciales y académicos. Lo que tal vez ofenda de dicha afirmación no será su falsedad, sino su generalización, en tanto 
debe haber casos de correspondencia entre posesión del cargo e idoneidad.

En 2012, el Congreso reformó el Consejo de la Magistratura por la Ley 26.855, volviendo a elevar el número, cuando justamente antes había expresado la reducción del número para ganar en eficiencia. Por ello, se ha dicho que la velocidad del cuerpo no se logra aumentando o disminuyendo el número de consejeros sino agilizando los trámites y logrando que los miembros asistan a las reuniones. Ahora tiene un representante del PE, seis legisladores, tres jueces, tres abogados y seis representantes de los ámbitos académicos y científicos. Se elevó el número de trece a diecinueve, con la novedad de que los miembros serían elegidos por voto popular. Si se cae en la cuenta de que el PE y el Congreso son elegidos por el pueblo y se suma a ello la elección popular de los encargados de remover a los jueces, puede ocurrir que las mayorías populares puedan apropiarse de la "suma del poder público". El cuerpo electoral elige a los legisladores, que a su vez integran el Consejo y la Constitución justamente incorpora a jueces, abogados y académicos para equilibrar la representación política (art. 114, CN.), que la nueva ley somete a elección popular, alterando el equilibrio. "[...] el precepto no contempla la posibilidad de que los consejeros puedan ser elegidos por el voto popular ya que, si así ocurriera, dejarían de ser representantes del sector para convertirse en representantes del cuerpo electoral" (consid. 18), dice la CSJN en "Rizzo, Jorge s/acción de amparo c. PEN, Ley 26.855, medida cautelar", fallado el 18 de junio de 2013. Se sabe que los titulares del PE suelen ser quienes tienen a su cargo la jefatura de los partidos políticos que a su vez promueven a los candidatos a los cargos de legisladores, con lo cual una sola persona concentra gran parte del poder político. La Política se ve como acumulación del poder y la Justicia se ve como límite a fin de que se respete la igualdad entre los iguales y los distintos. Como lo señala la Corte, la intención del constituyente de 1994 fue despolitizar la elección de los jueces, para lo cual se vale del Consejo de la Magistratura donde se visibiliza el procedimiento, con los concursos, los antecedentes, las oposiciones y las entre- 
vistas, lo que otorga transparencia, en comparación con la anterior designación presidencial y el acuerdo del Senado. La CSJN ve la Política como ocultamiento, partidismo y falta de idoneidad.

[...] no ha dado lugar a controversias que la inserción del Consejo de la Magistratura como autoridad de la Nación ha tenido por finalidad principal despolitizar parcialmente el procedimiento vigente desde 1853 para la designación de los jueces, priorizando en el proceso de selección una ponderación con el mayor grado de objetividad de la idoneidad científica y profesional del candidato, por sobre la discrecionalidad absoluta [...] (consid. 20).

En vinculación con el espíritu de la distinción que Goldschmidt hace de Política y Derecho, señala coincidentemente la Corte en Rizzo: “[...] que los representantes de los órganos políticos resultantes de la elección popular no puedan ejercer acciones hegemónicas o predominar por sobre los representantes de los jueces, de los abogados y de los académicos o científicos, ni viceversa" (consid. 28). También señala que con la elección popular se obliga a los jueces a intervenir en la lucha partidaria (consid. 29), comprometiéndose su independencia. "En un Estado de justicia no debe haber sino un mínimo de puestos políticos; por ejemplo, los de ministros y subsecretarios" (Goldschmidt, 1986a, p. 290).

14. También el jurista germano-español señala que si bien los asuntos vitales son materia de los actos de gobierno, y como tal

[...] no caben reglas generales a priori; pero sí corresponde el control judicial a posteriori, toda vez que la solución de un asunto vital está sometida a los criterios del Derecho natural. Por ello, aunque tal vez durante una guerra el gobierno no estuviese sometido a la Constitución (conforme lo afirma la Corte Suprema de Justicia en el caso Merck), siempre está subordinado al Derecho Natural (Goldschmidt, 1987, pp. 76-77).

15. Con respecto a la presunción que cabe a los políticos, no es la de la justicia de sus actos. A ellos cabría asignarles una falta de preferencia óntica de sus repartos. 
En la lucha por el poder vencen normalmente los malos sobre los buenos. La razón está en que los malos solo combaten a los demás, mientras que los buenos, además, luchan contra sus propios instintos malos; por ello el empuje de los malos es más fuerte que el de los buenos (Goldschmidt, 1986a, p. 323).

16. Cuando Goldschmidt se refiere al poder lo califica como "[...] un valor natural relativo. Ello quiere decir que el poderoso puede usar su poder tanto para algo bueno, como para algo malo. Poder sin justicia es satánico, poder con justicia es divino" (Goldschmidt, 1987, p. 61). Dice Weber "quien hace política aspira al poder; al poder como medio para la consecución de otros fines (idealistas o egoístas) o al poder 'por el poder', para gozar del sentimiento de prestigio que él confiere" (Weber, 1995, pp. 84, 156-157). Ya Cicerón decía que la mayor parte olvida la justicia cuando se convierten en víctimas de los mandos, los honores y la gloria (Cicerón, 1994, p. 16).

Goldschmidt hará de la Política un bastión de la Justicia, relativizándola, en lugar de convertirla en la coordinadora de las restantes ciencias, como lo propongo.

Una adjudicación o un orden de adjudicaciones no solo son justos o injustos, sino que resultan también convenientes o inconvenientes para el logro, la conservación o el aumento del poder. La totalidad de las adjudicaciones, en cambio, es exclusivamente susceptible de la valoración dikelógica, ya que una totalidad reclama a un valor absoluto como la justicia y no resulta asequible a un valor relativo como lo es lo político (Goldschmidt, 1978, p. 56).

17. Morin coincide con la crítica goldschmidtiana de la política ordinaria cuando habla del Estado: "se puede y se debe concebir una humanidad que se vea libre de los Estados, pero no se puede concebir a medio plazo una política al margen del sistema y el contexto de los Estados nacionales [...]" (Morin, 2002, p. 84). En otra oportunidad señala que: "[...] todo conocimiento simplificante y, por tanto, mutilado, es mutilante y se traduce en una 
manipulación, represión, devastación de lo real, desde el momento en que se transforma en acción y singularmente en acción política" (Morin, 1993, p. 436).

18. Haciendo una crítica al partidismo, Goldschmidt remarca al hombre cosmocéntrico, que bien se puede calificar como el hombre complejo, que realiza la política compleja o ciencia de la transdisciplinariedad.

El hombre egocéntrico se fortifica dentro de su individualidad y emplea toda su vida para afianzarla y vigorizarla, oponiéndola en todo momento al mundo circundante. He aquí el grupo de personas al que pertenecen los hombres partidistas de todas filiaciones que creen apasionadamente en la verdad de una doctrina y rechazan con idéntica pujanza la contraria [...]. El hombre cosmocéntrico [...] se deshace de su personalidad individual y se diluye en el mundo entero identificándose con él en todas sus manifestaciones. Con amor infinito y comprensión inagotable abarca todo; acepta todo, al menos a los efectos de un examen imparcial y limpio de prejuicios. [...] Dentro de lo posible armoniza discordias (Goldschmidt, 1953, p. 121).

De manera que sin eticidad, ética, compromiso personal, es difícil sostener una sociedad en la que haya justicia. Lo propio ocurre analizando el tema desde el punto de vista de las razones de los repartos, cuando los móviles de los repartidores no coinciden con las alegaciones. La excesiva distancia contribuye a la desconfianza social y no facilita la convivencia. Recuérdese la ley que aumentaba el número de miembros de la Corte en la administración Menem y cómo fue un elemento clave de la desconfianza de sus decisiones, que finalmente fue un elemento que le jugó en contra. Y precisamente las actitudes éticas y los móviles transparentes son los temas dejados al ámbito de la ciencia de la articulación, la ciencia de la transdisciplinariedad, que es necesario transparentar.

En este sentido, la política sería como la ética colectiva, en donde la comunidad piensa los lazos íntimos que la mantienen unida. 
Sin compromiso ético o político no es posible la justicia. De esta manera, se va adelantando la respuesta a la pregunta inicial. "La toma de consciencia puede comenzar entonces en todo hombre de buena voluntad" (Morin, 2002, p. 101). Señala Weber:

$[\ldots]$ en este mundo no se consigue nunca lo posible si no se intenta lo imposible una y otra vez. [...] han de armarse desde ahora de esa fortaleza de ánimo que permite soportar la destrucción de todas las esperanzas, si no quieren resultar incapaces de realizar incluso lo que hoy es posible. [...] solo quien frente a todo esto es capaz de responder con un 'sin embargo' [...] tiene 'vocación' para la política (Weber, 1995, pp. 178-179).

Por ello, la Política debe incorporarse al Derecho y el Derecho a la Política. En este sentido, el trialismo es una teoría jurídica más permeable a las comunicaciones con la Política que otras teorías purificadoras, separadoras.

Estos acercamientos esporádicos entre la Política y el Derecho anticipan el mayor contacto entre estas dos disciplinas que hará el discípulo de Goldschmidt, Miguel Ángel Ciuro Caldani.

\section{El continente político del Derecho. La política jurídica}

1. En una posición menos crítica hacia la Política, Ciuro Caldani la plantea como el continente del Derecho. "[...] es indispensable la reintegración del universo de la convivencia — del 'continente' del Derecho-y por razones históricas y etimológicas el término más adecuado para designarlo es 'política"' (Ciuro Caldani, 1976, p. 35). En otra ocasión señala el jurista rosarino que el Derecho es una rama especial de la Política, que se caracteriza por una particular manera de considerar dicho continente de la convivencia, que se traduce en hacer de la justicia el centro de la relación de exigencia (Ciuro Caldani, 1976, p. 137).

Concuerdo con Ferrater Mora cuando describe a la Política como la encargada de "[...] la organización de los seres humanos en 
sociedades" (Ferrater Mora, 1994, p. 2833), aunque no cuando incluye como su tema "particular" "[...] las cuestiones suscitadas por el mando [...] de unos hombres sobre otros para realizar ciertos fines comunes" (Ferrater Mora, 1994, p. 2833). Esto no incluye a las teorías anarquistas. Goldschmidt ha resaltado que el orden también puede lograrse a partir de la espontaneidad de las relaciones horizontales, como lo demuestra la costumbre (Goldschmidt, 1987, pp. 90-97; Galati, 2015).

Aristóteles ha dicho que habría menos necesidad de actos justos si los hombres fueran amigos, con lo cual, la justicia parece absorberse en la amistad. Al fundamentar la no absorción de la Política por el Derecho, señala Ciuro Caldani:

[...] no creemos conveniente que ensanche [la ciencia jurídica] sus fronteras para abarcar toda la problemática de la convivencia, ya que en este caso se corre el riesgo de que el amor, valor supremo de la vida en común, que debe superar — no ignorar- la justicia del Derecho, sea confundido con la mera masificación (Ciuro Caldani, 1976, p. 36).

1.1. Morin coincidiría con Ciuro Caldani cuando plantea algo más que la "inteligencia": "[...] el hombre no solo tiene necesidad de más inteligencia, necesita también más comunicación, más participación, más amistad, más amor” (Morin, 2002, p. 42). En efecto, "[...] la única réplica, que no respuesta, a la angustia, es el amor, es la participación" (Morin, 2002, p. 71). Aquí también habría coincidencia con el jurista germano-español, que reclama que la justicia no puede sustentarse sin una ética de fondo, sin el amor, sin la convivencia; y que reclama al jurista mayor involucramiento.

2. Ciuro Caldani distingue a la Política del Derecho por el valor particular de cada una, que en el primer caso es la convivencia y en el segundo la justicia (Ciuro Caldani, 1976, p. 27).

2.1. La Política compleja o ciencia de la transdisciplinariedad es un ámbito de convivencia. Prefiero el término ciencia de la 
transdisciplinariedad. "[...] si una política puede sujetar todos los aspectos de la vida de una sociedad, no puede asumir ni resolver la totalidad de los problemas humanos" (Morin \& Kern, 2006, p. 160). En efecto, no pueden reducirse todas las dimensiones a la Política, en tanto hay temas que escapan a ella (Morin \& Kern, 2006, p. 163). Por otra parte, la transdisciplinariedad es la que permite un lenguaje común a todas las ciencias. Morin señala la necesidad de "[...] religar — religere - a la humanidad consigo misma y con la esfera del misterio [...]" (Morin, 2002, p. 43). Por ello, "[...] el desarrollo del ser humano mostrará ser el discurso mismo de la nueva política [...]" (Morin, 2002, p. 64), más allá del desarrollo económico (Morin, 2002, p. 64). "El Tercer Mundo ha hecho aflorar al plano consciente el problema del subdesarrollo económico; pero al mismo tiempo, en Extremo Occidente, el propio desarrollo económico comienza a revelar un fantástico subdesarrollo afectivo, psicológico y moral del ser humano" (Morin, 2002, p. 65). Estos principios pueden implicar solidaridad ambiental, con la firma del protocolo de Kyoto, y solidaridad económica, hacia el África negra y otros países con deudas imposibles de pagar, salvo con el sacrificio de la vida de la población.

La ciencia de la transdisciplinariedad puede ser el ámbito de integración de las distintas ciencias, sin que haya un ámbito en el que una ciencia se arrogue competencias de las demás, sometiéndolas a sus objetivos distintivos. Por ejemplo, se señala el caso de la economía, que guía al mundo actual y absorbe lo político (Morin \& Kern, 2006, p. 161). "[...] la política se vació de las grandes ideas en beneficio de objetivos económicos que se volvieron prioritarios: estabilidad de la moneda, tasas de crecimiento, balanza de comercio exterior, productividad de las empresas, competitividad en el mercado internacional" (Morin \& Kern, 2006, p. 161).

A su vez, esa ciencia de la transdisciplinariedad, no solo es tal por aunar disciplinas distintas, a las que debe coordinar, sino porque incluye lo que todas han excluido: lo imaginario, el mito, la subjetividad. 
$[\ldots]$ si es cierto que el mito no es una superestructura sino una de las instancias producidas y productivas, causantes y causadas en el bucle autoorganizador de la cultura y de la sociedad, si es cierto que la afectividad, el amor y el odio no dan cuenta solamente de contingencias privadas sino que constituyen una parte vital de lo humano, entonces la política no puede considerar los problemas solamente en el nivel prosaico de lo tecnológico, de lo económico, de lo cuantitativo (Morin \& Kern 2006, p. 162).

3. Además, Ciuro Caldani incluye a la oportunidad como elemento de la ciencia política (1976, p. 27). El marco que brinda el Derecho trialista incluye la oportunidad, a la hora de categorizar el origen de los repartos en el proceso de reconocimiento, decisión y efectivización del mismo (2000, p. 60). También incluye a la estrategia (1976, p. 35), la visión de conjunto de los repartos. En el funcionamiento de las normas prevé la resistencia al principio de hermeticidad con la carencia histórica de normas, y la resistencia a la normatividad injusta con la carencia dikelógica de normas; lo cual no debe olvidar que la decisión se enmarca en una táctica adecuada a la situación.

4. La consideración de la Política como el continente del Derecho es coherente con el hecho de introducir en la justicia el elemento del consenso por parte de Ciuro Caldani (2007, pp. 13 y 15). Esta idea tiene la ventaja de invitar al diálogo, al pacto, al acercamiento, al intercambio, a la convivencia. Deberíamos cuidar que esta relación no implique el peligro de identificar la razonabilidad social —los criterios de justicia que imperan en una sociedad determinadacon la justicia, lo que podría implicar legitimar desde el consenso cualquier régimen. Por ello veo en Ciuro Caldani un trialismo postmoderno, flexible, no tan duro como el de Goldschmidt. Tal vez sea la expresión de nuestro tiempo. Si bien el jurista rosarino señala que las bases compartidas respecto de la justicia no implican unirla a la dimensión sociológica, considero que el valor, separado del consenso, rígido en su estructura, es lo que permitirá la crítica (Galati, 2007, pp. 101-106). Dicha crítica solo es posible si no se confunde con aquello que tiene que criticar: el poder de 
quienes hacen las normas, que son los que generalmente juzgan acerca de la oportunidad y la conveniencia, que muchas veces no es la justicia, ni la evaluación de la oportunidad y conveniencia que realiza el pueblo.

5. Pienso que la Política no debe confundirse por completo con el Derecho, porque de lo contrario la justicia, el Poder Judicial, se teñiría de cuestiones partidistas. Lo cual ha tenido un correlato en nuestro país con las "cuestiones políticas no judicializables". Sin justicia no puede construirse un país. Prueba de ello es lo que ha ocurrido con la impunidad de los delitos de lesa humanidad cometidos y planeados por el gobierno de facto argentino de 1976-1982. En este caso, el no juzgamiento significaba el constante peregrinar de pedidos de gran cantidad de personas que no hallaban consuelo. Así como no hay libertad, si no hay libertad para todos, tampoco habrá amor, si no hay justicia para todos. En este sentido la justicia es un presupuesto del perdón. Así lo entendió la CSJN en el caso "Arancibia Clavel", fallado por la CSJN el 24 de agosto de 2004.

6. Mostrando la vinculación de la Política con otros saberes, Morin resalta la vinculación entre el saber y el poder. Se pregunta el creador del pensamiento complejo:

¿Cómo es que la ciencia sigue siendo incapaz de concebirse como praxis social? ¿Cómo es incapaz, no solamente de controlar, sino de concebir su poder de manipulación y su manipulación por los poderes? ¿Cómo es que los científicos son incapaces de concebir el vínculo entre la investigación 'desinteresada' y la investigación del interés? ¿Por qué son también totalmente incapaces de examinar en términos científicos la relación entre saber y poder? (Morin, 1993, p. 27).

6.1. El jurista rosarino ha escrito un artículo titulado "El saberpoder y el drama de la Universidad argentina" (Ciuro Caldani, 1992, pp. 46-47). Aquí contesta la pregunta moriniana resaltando que: 
[...] quien desee adquirir poder sin contar con una buena posición social podrá emplear el camino relativamente fácil de la adquisición del saber. Es notorio, por ejemplo, cómo el saber, sobre todo a través de la educación gratuita, ha servido en nuestro medio para la promoción social y la reforma del poder (Ciuro Caldani, 1992, p. 46).

6.2. Estas ideas demuestran cómo el poder puede ser un instrumento para la reforma de una situación dada. De allí que se hable de la sociedad del conocimiento, como el nuevo factor de poder de este siglo. No por casualidad, la gratuidad de la educación universitaria es un tema clave en relación con el poder. Aunque debemos superar el ocultamiento que produce la gratuidad formal de la onerosidad material, si se analizan los presupuestos del acceso a dicha educación de alto nivel. Un habitante de una villa miseria difícilmente pueda acceder a la Universidad ante la sola declaración por las normas de la gratuidad, ya que existen trabas económicas que son más profundas que los meros aranceles que bien podrían sortearse con becas o exenciones ad hoc justificadas. Tal vez dicha persona no cuente con la educación media previa y necesaria, ni con los alimentos para que el cerebro funcione adecuadamente, $\mathrm{o}$ el transporte para acercarse desde su núcleo habitacional al lugar de la Universidad, cuyas facultades generalmente están ubicadas en el "centro" de las ciudades. Tal vez tampoco cuente con el tiempo necesario de dedicación al estudio, que no se agota en la asistencia a clases; tiempo que deberá alternar con el trabajo, si es que cuenta con la suerte de tenerlo. Esto revela que la mera declaración en los textos de la gratuidad no soluciona mágicamente el problema. En el caso "Estado Nacional s. formula observación al estatuto de la Universidad Nacional de Córdoba", fallado por la Corte el 27 de mayo de 1999, donde el PE observa el estatuto de aquella Universidad porque no consagraba expresamente la "equidad" en la enseñanza universitaria, la mayoría (automática) de la Corte hizo referencia a lo que los constituyentes del año 1994 pretendieron al establecer dicho concepto. "El principio de equidad, que se suma al de gratuidad, cumple una función que deriva de su significado: la justicia; y consiste en una directiva, en 
aquellos casos en que la gratuidad no alcance por sí sola a garantizar la igualdad de oportunidades, se impone al Estado la carga de proveer a los habitantes de los medios suficientes para acceder a la educación gratuita" (consid. 8). Aunque falló en sentido contrario. Urge entonces abordar también el problema desde su ángulo jurístico-sociológico.

7. Tal vez, la intención última es que "[...] el proceso del poder pueda ser juzgado" (Ciuro Caldani, 1976, p. 48). Ya se puede vislumbrar cómo las dos concepciones, desde sus propios ángulos, se acercan a su "relativamente opuesta". Será entonces tarea del pensamiento complejo aunarlas, complementándolas.

\section{La ciencia de la transdisciplinariedad}

1. A pesar de las posturas nominales de Goldschmidt y Ciuro Caldani en la relación entre el Derecho y la Política, hemos visto cómo hay pequeñas concesiones, que pueden aventurar una convivencia dialógica. Y para ello es una herramienta útil el pensamiento complejo:

El pensamiento complejo piensa por medio de macroconceptos, es decir por medio de la asociación de conceptos atómicos separados por regla general, antagonistas a veces, pero que en su interrelación generan figuras complejas que sin esa dinámica interactiva se volatilizan y dejan de existir. Los macroconceptos asocian conceptos que se excluyen y se contradicen, pero que una vez críticamente asociados, producen una realidad lógica más interesante y comprensiva que por separado (Morin, Ciurana \& Motta, 2002, p. 52).

2. Señala Morin: "hay que plantear el desarrollo como noción total y multidimensional [...]" (Morin, 2002, p. 65). Es necesario un ámbito en el que fluyan los saberes, sin aduanas, sin barreras, con diálogo, a fin de que no se cieguen. "En la complejidad de nuestro tiempo el saber jurídico no puede mantenerse aislado de las otras disciplinas interhumanas" (Ciuro Caldani, 1976, p. 5). Y dicho 
ámbito central es la ciencia del hombre (Morin, 2002, p. 123). "La antropo-política [...] será fuerza de comunicación y comunión" (Morin 2002, p. 45). Coincidentemente dice Ciuro Caldani "Si el hombre ha de estar a la altura de la situación ha de permeabilizar todos los compartimentos que escinden su saber y ha de surgir la "ciencia de lo universal"' (Ciuro Caldani, 1976, p. 29). Para que el hombre no sea un mero técnico, que aplica resultados parciales de una especialidad, ni un mero científico, que conoce el ámbito delimitado de la especialidad, pero que no se preocupa del contenido ideológico de los recortes que la circunscriben, sino un sabio que trata de encontrar la más plena realización de la verdad en ese sector (Ciuro Caldani, 1976, p. 82).

3. Lo contrario ha implicado que "la cristalización institucional, dogmática, política, del amor religioso [...] ha[ya] podido convertirse parcialmente en fanatismo, en odio y en hogueras" (Morin, 2002, p. 43). Esto puede ocurrir con el costado negativo de la Política que resalta Goldschmidt, que exhibe la mecánica del partido, del poder. Lo que le pasa al partido con la Política, es lo que le pasa a la fe con la Iglesia. Debe cuidarse de que el partido no ahogue el pensamiento y el diálogo, y que la Iglesia no ahogue la fe. La iglesia ahoga la fe, por ejemplo, cuando la ritualiza, cuando la desarrolla de una manera no comprensible para el creyente. Lo propio ocurre con el partido cuando no toma contacto con el afiliado, realizando internas abiertas, cuando capta dirigentes, cuando no hay padrones claros, debates de ideas, capacitación gratuita y plural de sus dirigentes, etc. El partido se cristaliza cuando no toma contacto con la sociedad con internas abiertas, cuando no publicita sus recursos, es decir, ingresos y gastos.

3.1. Las Fuerzas Armadas deberían poder votar y opinar respecto de las cuestiones públicas. Esto llama a no tener visiones pendulares, en las que las FF.AA. han llegado a gobernar, y momentos en que son vistas como el enemigo público al que hay que someter.

3.2. Negar expresión político-partidaria a los jueces es también un síntoma de hipocresía, que se une al hecho de que sus decisiones 
no deben estar fundadas en la justicia, y sí en la norma, que muchas veces es interpretada a su antojo.

Históricamente, esta tendencia se explica por la concepción del Poder Judicial como órgano neutro del Estado [...] o la doctrina de Maurice Hauriou del Poder Judicial como poder no político del Estado (en oposición a los poderes 'políticos' en el gobierno: legislativo y ejecutivo) (Sagüés, 1978, p. 7).

La apoliticidad formal solo escondía la extrema politicidad fáctica de dicho poder. Porque eran nombrados por funcionarios políticos, y porque no pueden sustraerse a la complejidad de la vida, a la Política. Toda cuestión política es judiciable, así como toda cuestión jurídica es politizable.

4. "Una política del hombre total, que pretenda abarcar todos los aspectos de la vida [...] si quiere evitar reducir de forma brutal a la dimensión $[\ldots]$ cívica $[. .$.$] todas las demás dimensiones del$ hombre, no solo debe concebir la existencia de esferas distintas sino admitir que son heterogéneas [...]" (Morin, 2002, p. 72). La humanidad es más que la justicia.

[...] la vida humana individual y colectiva requiere imprescindiblemente momentos (la infancia, la guerra, etc.) en que el recipiendario ha de recibir más de lo que merece desde un punto de vista de justicia restringido. No hay regla de reparto que pueda prever el amor necesario para hacer un niño feliz o para lograr una victoria (Ciuro Caldani, 1976, p. 72).

5. Hoy como nunca es más evidente el problema del destino humano (Ciuro Caldani, 1976), que reclama la integración de las disciplinas y la complejidad en las disciplinas. El ámbito de dicho diálogo es la ciencia de la transdisciplinariedad o política compleja. Morin incluye como inherente a la Política la duda y los interrogantes (Morin, 2002), lo que no es común en algunos ámbitos políticos, en los que el dogma doctrinario gobierna, o la lucha o quiebres son los resultados de las disputas. La transdisciplinariedad signi- 
fica ir más allá de las disciplinas sin ser una disciplina (Nicolescu, 2000), permitiendo pasarelas, transferencias, relaciones, lenguajes, acuerdos, entre las disciplinas.

5.1. La ciencia de la transdisciplinariedad puede ser el ámbito en donde se discuta, por ejemplo, el problema del hombre consumidor.

La gigantesca masa salarial vinculada a las gigantescas organizaciones elige una opción fundamental. Esa opción viene predeterminada por el sistema (capitalista) y por la civilización (burguesa), [...] el asalariado prefiere consumir a dirigir la empresa, el goce a la responsabilidad, el completo desarrollo de su vida privada al completo desarrollo de su vida cívica (Morin, 2002, p. 88).

Y esto tiene un correlato inmediato en el Derecho, porque si somos menos técnicos y más sabios, participaremos con los políticos en la elaboración del Derecho, habrá menos cuestiones políticas, y sí más públicas, más humanas. Algunos plantean un estado de conformismo:

¿Quién los ha convencido [a los juristas] de que desempeñan en la sociedad un papel mesiánico [...]? [...] tiene facultad, como cualquier ciudadano, para concebir y expresar sus propias ideas. Pero [...] una sociedad espera demasiado de sus juristas, jueces y abogados cuando aprende a esperar demasiado poco de sus gobernantes. En los sistemas políticos actuales, existe un mecanismo especialmente diseñado para facilitar el cumplimiento de las condiciones pragmáticas del ejercicio del poder: es la democracia, que permite a los ciudadanos guiar el rumbo de los gobernantes, controlar su gestión y hallar un fundamento razonable para el acatamiento (Guibourg, 2002, pp. 132-133).

Cuando se refiere a la clásica polémica entre el liberalismo y el socialismo, señala Morin: 
[...] la hiperconcentración de la economía comienza a controlarse, a orientarse, a veces incluso a gestionarse desde el Estado. Este concentra cada vez más competencias y atribuciones bajo su mano. En el Este, el Estado empieza a descentralizarse, la economía comienza a solicitar iniciativas y mecanismos de mercado [...] (Morin, 2002, p. 82).

La remisión a EE.UU. luego de la crisis hipotecaria y quiebra de varias instituciones bancarias en 2008, y a China, que abre sus puertas al capitalismo resulta inevitable. Aparentemente, el mundo iría hacia un sistema económico complejo.

5.2. La diversidad familiar es un gran interrogante, junto al de los modos de producción y vida, urbano y agrario. Otro ejemplo de cuestión compleja, por la temática y por el ámbito es el de la especie. Es compleja porque incluye diversos aspectos que pueden modificarse con los avances genéticos: el afecto, la inteligencia, el cuerpo, el espíritu, tanto al interior como al exterior del ser humano.

La naturaleza psicoafectiva del hombre se encuentra ya en el radio de acción de la química. [...] hoy en día se puede profetizar que se producirá, más allá de las actuales acciones químicas sobre el sistema neurovegetativo (tranquilizantes, euforizantes, hipnóticos, extasiantes), una acción sobre el carácter, sobre lo que llamamos la naturaleza del hombre (Morin, 2002, p. 52).

Es extremadamente simplificador creer que dicho problema se encuentra resuelto por el decreto de necesidad y urgencia argentino 200/97 de prohibición de experimentos de clonación relacionados con embriones humanos. Estamos frente a " [...] la posibilidad radical de la superación del hombre por el hombre [...]" (Morin, 2002, p. 50). Un corolario de este tema es que todo puede cuestionarse, incluso a Dios (Morin, 2002, p. 49).

$[\ldots]$ ya es posible pensar [...] en una intervención en el ADN, es decir, se puede ya pensar en el gigantesco, fantástico y profundo 
problema de la modificación del ser genérico, de la transformación de una especie de la que aún podemos decir, [...] que sigue siendo humana (Morin, 2002, pp. 52-53).

6. El pensamiento complejo es el ámbito en el que pueden convivir la posición de Ciuro Caldani y la de Goldschmidt, lográndose la complementariedad. Dice Morin, rememorando estas dos posiciones: "Existe una necesidad de una conciencia revolucionaria que pueda domesticar a la ciencia. Sin embargo, y recíprocamente, esa conciencia debe aprender de la ciencia [...] buscar también en la ciencia el complemento que pudiera resultar decisivo para la revolución" (Morin, 2002, p. 48). El costado de poder de la Política, como el costado del amor en la convivencia, pueden confluir en la ciencia de la transdisciplinariedad: “[...] en el más íntimo tejido de la ciencia encontramos, vinculadas y opuestas, dos infraestructuras: una es la psique y el sueño, y la otra es el desarrollo técnico y económico" (Morin, 2002, p. 49).

\section{Cuestiones políticas ¿judiciables o no judiciables?}

1. Los indultos, las intervenciones federales, las leyes secretas, el control de los DNU, etc., han sido siempre actos públicos calificados como inanalizables por los jueces invocando ser "cuestiones políticas” y, por ende, no justiciables. Dice Sagüés explicando la doctrina:

En rigor de verdad, estas cuestiones están sometidas a un control de constitucionalidad que no esjudicial: los 'jueces' de su constitucionalidad son, según los casos, el Congreso o el presidente. El Poder Judicial ha entendido que son esos poderes quienes exclusivamente deben juzgar la constitucionalidad de dichos asuntos (Sagüés, 1999, p. 283).

1.1. Juez alguno puede permitir una injusticia. De manera que no tendría sentido expresar lo que dice un juez del caso de los exploradores de cavernas. Si bien es malo, injusto, disvalioso, el asesinato, no puede pensarse lo mismo en estado de necesidad exculpante. Incluso, cuando un jurado decide condenar a los que 
asesinaron a uno de los exploradores, y luego peticiona el indulto (Fuller, 1991, p. 16), expresamente está reconociendo la injusticia de la decisión. Señala: "En casos como el presente la clemencia ejecutiva aparece admirablemente adecuada para mitigar los rigores de la ley [...]" (Fuller, 1991, p. 17). Esta actitud implica evadir la responsabilidad inherente a la función de jurista.

Las palabras del jurado no pueden ser más claras en referencia a la disociación y la huida acerca de las consecuencias de las decisiones: "Creo por lo tanto que podemos asumir que alguna forma de clemencia se acordará a estos acusados. Si así ocurriere, se hará justicia, sin menoscabo de la letra ni del espíritu de nuestra ley y sin ofrecer estímulo a su transgresión" (Fuller, 1991, pp. 17-18).

1.2. La actual CsjN ha incorporado la justicia al Derecho al cuestionar y declarar la inconstitucionalidad del indulto que firmó el expresidente Carlos Menem a Santiago Riveros por el decreto 1002/89. Se trató de un militar argentino que alcanzó el grado de comandante de institutos militares en Campo de Mayo, durante el régimen de facto de 1976-1983. El problema del caso giraba en torno a que un tribunal ya se había pronunciado sobre la validez del indulto en 1989, generando cosa juzgada y un derecho adquirido, además de sostenerse que no puede cuestionarse la facultad presidencial de indultar, que no se limita por tratarse de un delito contra la humanidad. Se aludió al contexto de guerra en que sucedieron los hechos imputados, lo que habilitaba solo la jurisdicción militar. Además, no se atacó a la población civil, sino que se pretendió aniquilar el terrorismo. Se alude a las normas relativas a la prescripción de la acción, y se señala que no puede desconocerse el derecho positivo alegando el derecho natural. En el caso "Mazzeo, Julio y otros s. recurso de casación e inconstitucionalidad", fallado el 13 de julio de 2007 por la CSJN, esta señaló que la competencia militar es de excepción y limitada al resguardo del orden y los bienes jurídicos castrenses (consid. 7). Cuando se refiere a la obligación de protección de los Estados de los DD.HH., dice: "[...] hay principios que determinan la justicia de las instituciones sociales y establecen parámetros de virtud 
personal que son universalmente válidos, independientemente de su reconocimiento efectivo por ciertos órganos o individuos, lo cual no implica optar por excluyentes visiones ius-naturalistas o positivistas [sic] [...]" (consid. 13). El derecho de gentes, incorporado por el actual art. 118 de la CN incorpora la violación de crímenes contra la humanidad, incluso en épocas de guerra (consid. 15). Resalta la Corte un orden normativo y práctica consuetudinaria internacional sobre el tema, al tiempo de la comisión del delito de Riveros (consid. 16). Señala la preeminencia de las normas internacionales, a partir del caso "Ekmekdjian" (consid. 20); por lo que la norma suprema es la Convención (consid. 21). Menciona que los delitos contra la humanidad van más allá de lo tolerable (consid. 23), lo que se relaciona con el mínimo de justicia que el ordenamiento normativo debe respetar, para no convertirse en una tiranía aceptable, por el mero hecho de ser "puesta". Es dable rescatar que se dijo que la impunidad propiciaba la repetición de tales conductas (consid. 25). "[...] dicho acto de gobierno [indulto] conlleva de modo inescindible a la renuncia a la verdad, a la investigación, a la comprobación de los hechos, a la identificación de sus autores y a la desarticulación de los medios y recursos eficaces para evitar la impunidad" (consid. 29). Entiendo que en el caso se ha utilizado el costado de poder o arbitrario de la Política, como lo señala la Corte: “[...] los delitos que implican una violación de los más elementales principios de convivencia humana civilizada, quedan inmunizados de decisiones discrecionales de cualquiera de los poderes del Estado que diluyan los efectivos remedios de los que debe disponer el Estado para obtener el castigo [...]" (consid. 31). La misma Política que es jerarquizada en su costado humanitario. El Alto Tribunal señala que al momento de dictarse el indulto se encontraban vigentes la Convención Americana de Derechos Humanos (1984) y el Pacto Internacional de Derechos Civiles y Políticos (1986). Cuando la Corte tiene que referirse al argumento de la cosa juzgada, señala que si bien también está garantizada por los instrumentos internacionales, no debe haberse obtenido mediante fraude, es decir, un delito, y que debe ceder a la razón de justicia (consid. 33). Señala así la pauta de judiciabilidad de estos delitos contra la humanidad. 
2. Goldschmidt y su discípulo Bidart Campos están más a favor de la judicialización de las cuestiones políticas, que son tales por los problemas fundamentales que tratan. Y en este sentido es acertada la visión:

[...] en el caso de la guerra, la constitución solamente exige que la declare el ejecutivo con autorización del congreso, pero nada dice sobre los casos, causas, oportunidades y condiciones que hacen procedente la declaración y realización de la guerra; entonces, cuando constitucionalmente la guerra está bien declarada, los jueces no tienen materia que sea objeto de su control, porque hay un campo de discrecionalidad librada al juicio y a la prudencia de los órganos que conducen y realizan la guerra. Al faltar el marco de condicionamiento y encuadre [...] no hay campo para eventual violación de la constitución, y entonces, no aparece la cuestión constitucional (Bidart Campos, 1986, p. 84).

3. Mi posición va más allá y coincide con Goldschmidt, en tanto Bidart propone una judicialización normativa y yo propongo una judicialización trialista, que incorpore también el análisis valorativo. Si bien no podría ordenársele al Ejecutivo que no declare la guerra, porque no es competencia de los jueces declarar la guerra, sí podrían actuar en el caso concreto, por ejemplo, eximiendo del servicio militar a quien lo solicite por la ilegitimidad de la guerra, si es injusta. Nada impide que la horizontalidad del juicio respecto de la validez de la guerra prevalezca respecto de la verticalidad de la decisión de los supremos repartidores. En el otro extremo, se encuentran las posiciones que criticaba Bidart que eximían del control judicial, incluso cuando se han violado cuestiones procedimentales. Es la doctrina del caso "Cullen c. Llerena", fallado por la CSJN el 7 de septiembre de 1893, en donde el Congreso votó negativamente la intervención a Santa Fe, y luego sancionó otra norma positiva en aquel sentido, violando la disposición constitucional que prohíbe al Parlamento pronunciarse dos veces respecto de un mismo tema en un mismo ciclo parlamentario (art. 81, CN). 
4. Ciuro Caldani estaría más a favor de la no judicialización de las cuestiones que son políticas. Y Sagüés permitiría una postura similar a la que sostengo:

[...] cualquier 'cuestión política' tiene una dimensión normativoconstitucional (p. ej., órgano que puede dictarla; procedimiento para su sanción) [...]. Ello es [...] justiciable. También lo es si lo decidido respeta el mínimo de justicia y razonabilidad que la Constitución exige para que sea constitucional.

Planteado un conflicto judicial concreto, en el cual —ante un derecho constitucional violado- sea necesario evaluar la dimensión jurídica de una cuestión política, dicho examen, practicado por la judicatura, resulta una tarea obligada, que se debe realizar con la prudencia del caso, y partiendo de la presunción de legitimidad del comportamiento estatal (Sagüés, 1999, pp. 286-287).

En mi caso, me permito dudar de dicha presunción de legitimidad de los actos estatales, por la presunción de injusticia que contienen implícitas los repartos autoritarios. En tanto es propio del hombre aceptar mejor aquella regulación que él mismo se da, que no se basa en imposiciones. Además, mandar, imponer, significa invadir la esfera de libertad del individuo (Goldschmidt, 1987, pp. 69-70) que solo justificaría para el respeto de la igualdad.

5. La tarea del pensamiento complejo será crear una ciencia o ámbito de la complejidad/transdisciplinariedad en el que puedan convivir dialógicamente dichas posturas. La judicialización es un ámbito de discusión de lo político, pero no el único. También deben plantearse ámbitos de acuerdo, de diálogo, de convivencia y tolerancia, que sean soporte de la justicia, a la manera de la eticidad. En ocasión de la movilidad de las prestaciones jubilatorias, la Corte declaró la inconstitucionalidad del sistema de solidaridad previsional, y propuso al Congreso y Ejecutivo que sancionaran las normatividades del caso, evidenciándose cómo la justicia presiona, sugiere a la política. Este caso será la oportunidad de plantearse qué lugar ocupa el anciano en la sociedad. En otro 
caso, la aceptación por la Corte de la personalidad jurídica de una asociación travesti será el puntapié inicial a fin de que la sociedad debata respecto del problema de la integración del distinto. Una exigencia, que es jurídica, debe ser el ámbito del diálogo, que es político. Es una tensión social que debe requerir una respuesta. Una exigencia de justicia conlleva en el fondo un planteamiento acerca de lo humano. En el caso "ALITT", nos estamos preguntando por el destino humano. Los jueces han dado una respuesta aceptando la asociación. Un médico tal vez acepte el transexualismo, aceptando una operación de adecuación sexual. Pero es necesario que la sociedad se pregunte por dicho tema, porque la respuesta jurídica y la respuesta médica, incluso la psicológica también, no agotan el tema. Como señala Morin (2002, p. 122), no puede reducirse la política al gobierno y al ciudadano. Yo agregaría que en el caso de Argentina, las luchas electorales se centran en pases de facturas por los "errores" del pasado, en el cuestionamiento de las personalidades e inclusive intimidades de los candidatos - los primeros de las listas si el cuerpo es colectivo-, sin avanzar en los programas, ni en la pregunta clave acerca del destino humano, en cada una de las ramas de la vida.

6. Cabe agregar que la resistencia a la opresión es un acto político ejercido por sujetos no siempre partidarios, o al menos, no encargados de sancionar normas. En similar sentido, dice Ciuro Caldani que incluso la propiedad privada es una institución política fundamental, en tanto ayuda a organizar la cooperación, y remarca el rol político de los procesos judiciales (1976, p. 36). Por ello, todo jurista que "aplica" el Derecho Privado está consintiendo en una categoría básica del capitalismo. Una vez leí una pintada callejera que decía que todos los delitos son políticos.

\section{Conclusión}

Morin desarrolla en su libro Introducción a una politica del hombre, cuestiones filosóficas que trasuntan la pregunta por el destino del hombre, la condición humana, problemas que no pueden tratarse únicamente en el marco del Derecho que aborda la temática de la justicia. En este 
sentido, coincide con Ciuro Caldani en que la Política es el continente del Derecho, es decir, el lugar donde expertos de todas las disciplinas, y no expertos, decidan aquel destino, logrando la convivencia.

Pero, como pensador complejo, que abarca lo contradictorio en una unidad diversa, creo que Morin capta la posición de Goldschmidt, crítica de la Política, en tanto reclama participación de los ciudadanos y juristas en dicha problemática de la condición humana, del destino de la humanidad. Y allí se vería la actuación de la justicia, como límite a la Política, vista como partido o poder que, como instrumento flexible, valor relativo, puede derivar en arbitrariedades, oportunismos.

Se ve entonces el aspecto antropológico de la Política, desarrollado por Ciuro Caldani, y el aspecto institucional, desarrollado por Goldschmidt, y unidos ambos por el pensamiento complejo.

El destino del hombre es el problema, evidenciado por el ámbito de convivencia de la Política, que permite el ingreso de todas las disciplinas, y de la ciencia de la transdisciplinariedad como coordinadora de dichas herramientas de solución.

[...] la política se hace cargo [...] del devenir de los hombres en el mundo. Y el devenir del hombre en el mundo lleva consigo el problema filosófico, ahora politizado, del sentido de la vida, de las finalidades humanas, del destino humano (Morin \& Kern, 2006, pp. 159-160).

No hay destino humano sin justicia, pero la justicia no basta para resolver el destino humano. También podría llamarse a dicho ámbito de convivencia de las ciencias, la transdisciplinariedad, porque las relaciones humanas deben abordarse en su complejidad. La ciencia de la transdisciplinariedad podría tomar entonces la reflexividad de la Filosofía, y la participación de la Política, y marginando el elitismo de la primera, y el sometimiento de la segunda.

Así como Kelsen excluyó a la Política del Derecho, el trialismo pretende incluirla bajo el nombre de la justicia, por Goldschmidt, y como 
convivencia con otros valores, por parte de Ciuro Caldani. Mi tesis implica no separar la Política del Derecho, sino incluirla, como justicia y como ámbito de diálogo con otras disciplinas. Para ello se requiere un Derecho complejo, y una ciencia de la transdisciplinariedad.

\section{Referencias}

Bidart Campos, G. (1986). Tratado Elemental de Derecho Constitucional Argentino.

T. 1. El Derecho Constitucional del Poder, Buenos Aires: Ediar.

Cicerón, M. (1994). Sobre los deberes. (José Guillén Cabañero, Trad.). Barcelona: Altaya.

Ciuro Caldani, M. (1976). Derecho y Política. El continente político del Derecho. Elementos básicos de una filosofía política trialista. Rosario: Depalma.

Ciuro Caldani, M. (1992). El 'saber-poder' y el drama de la universidad argentina. Boletín del Centro de Investigaciones en Filosofía Jurídica y Filosofía Social, 15, 46-47.

Ciuro Caldani, M. (1991). La integración democrático-aristocrática. Boletín del Centro de Investigaciones de Filosofía Jurídica y Filosofía Social, 14, 21-22.

Ciuro Caldani, M. (2007). Metodología dikelógica. Métodos constitutivos de la justicia. Las fronteras de la justicia. Rosario: FIJ.

Ciuro Caldani, M. (2000). Metodología jurídica. Rosario: FIJ.

Ferrater Mora, J. (1994). Diccionario de Filosofía. T. III (K-P). Barcelona: Ariel. Fuller, L. (1991). El caso de los exploradores de cavernas. (Genaro Carrió y Leopoldo Niilus, Trads.). Buenos Aires: Abeledo-Perrot.

Galati, E. (2007). Una interpretación goldschmidtiana del objetivismo valorativo de Werner Goldschmidt. En M. Ciuro Caldani (Coord.), Dos filosofias del Derecho argentinas anticipatorias: homenaje a Werner Goldschmidt y Carlos Cossio (pp. 101-106). Rosario: FIJ.

Galati, E. (2015). La costumbre en el Derecho Argentino. Análisis jusfilosófico y trialista de la 'razón' del pueblo. Buenos Aires: Teseo.

Goldschmidt, W. (1953). Filosofía, Historia y Derecho. Buenos Aires: Valerio Abeledo.

Goldschmidt, W. (1978). Justicia y Verdad. Buenos Aires: La Ley.

Goldschmidt, W. (1986a). La ciencia de la justicia (Dikelogía). (2a ed). Buenos Aires: Depalma.

Goldschmidt, W. (1986b). Trialismo - Su semblanza, Enciclopedia Jurídica Omeba. Apéndice, t. V, 785-792. 
Goldschmidt, W. (1987). Introducción filosófica al Derecho (6 $\left.6^{\mathrm{a}} \mathrm{ed}\right)$. Buenos Aires: Depalma.

Guibourg, R. (2002). Provocaciones: en torno al Derecho. Buenos Aires: Eudeba. Kelsen, H. (1992). Teoría pura del Derecho (Moisés Nilve, Trad.). (29ºd). Buenos Aires: Eudeba.

Morin, E. (1993). El Método 1. La naturaleza de la naturaleza. (Trad. de Ana Sánchez en colab. con Dora Sánchez García). $3^{a}$ ed. Madrid: Cátedra.

Morin, E. (2002). Introducción a una política del hombre. (Tomás Fernández Aúz y Beatriz Eguibar, Trad.). Barcelona: Gedisa.

Morin, E. (2006). El Método 6. Ética (Ana Sánchez, Trad.). Madrid: Cátedra.

Morin, E., Ciurana, R. \& Motta, R. (2002). Educar en la era planetaria. El pensamiento complejo como método de aprendizaje en el error y la incertidumbre bumana. Valladolid: UNESCO - Univ. de Valladolid.

Morin, E. y Kern, A. (2006). Tierra-Patria. (Ricardo Figueira, Trad.). Buenos Aires: Nueva Visión.

Nicolescu, B. (2000), Transdisciplinarity and Complexity: Levels of Reality as Source of Indeterminacy. Bulletin Interactif $d u$ Centre International de Recherches et Études transdisciplinaires. 15. Recuperado de http://basarab. nicolescu.perso.sfr.fr/ciret/bulletin/b15/b15c4.htm

Raffo, J. (2007). 'Ideología y Derecho' -El libro perseguido de Carlos Cossio-. En M. Ciuro Caldani (Coord.), Dos filosofias... (pp. 205-215). Rosario: FIJ.

Sagüés, N. (1999). Elementos de Derecho Constitucional. T. 1. $3^{\text {a }}$ ed. Buenos Aires: Astrea.

Sagüés, N. (1978). Mundo jurídico y mundo político. Buenos Aires: Depalma.

Weber, M. (1995). Elpolítico y el científico. (Trad. de Francisco Rubio Llorente). Barcelona: Altaya. 